\title{
Enhancing inland navigation by model predictive control of water level the Cuinchy-Fontinettes case
}

\author{
K. Horváth, L. Rajaoarisoa, E. Duviella, J. Blesa, M. Petreczky and K. Chuquet
}

\begin{abstract}
Navigation canals are used for transport purposes. In order to allow safe navigation the water level should be kept in a certain range around the Normal Navigation Level (NNL). The water level is disturbed by known and unknown inputs, like tributaries, municipal water flows, rain, etc. Some of these inputs can be used to control the water level. If the geometry requires it, canal reaches are connected by locks. The operation of these locks sometimes can disturb the water level, if the difference between the upstream and downstream water level is large. The objective is to minimize the disturbances caused by these lock operations on the water level in order to maintain the NNL. In this work the global management of the canal reach is discussed and an option to maintain the NNL by active control is introduced. Some inputs to the system, such as other confluences or gates on the side of the locks, can be controlled automatically to react to the disturbances caused by the lock operations using model predictive control to maintain the desired water level.
\end{abstract}

K. Horváth, L. Rajaoarisoa, E. Duviella and M. Petreczky

Institut Mines Telecom Mines Douai, Bd. Lahure 747, Doaui, 59500, France, email: klaudia.horvath@mines-douai.fr, e-mail: lala.rajaoarisoa@mines-douai.fr, e-mail: eric.duviella@mines-douai.fr and e-mail: mihaly.petreczky@mines-douai.fr

J. Blesa

Technical University of Catalonia, Institut de Robtica i Informàtica Industrial, CSIC-UPC.

Llorens i Artigas, 4-6, 08028 Barcelona, Spain, e-mail: joaquim.blesa@upc.edu

K. Chuquet

VNF, e-mail: karine.chuquet@vnf.fr 


\section{Introduction}

Transport over water has considerable economical and ecological benefit [34], [32]. Navigation offers a more efficient, quieter, safer option for transport of goods. The transport over water consist of sea transport and inland navigation. In the following the latter will be analyzed.

In order to ensure navigation in inland canals the water level should be kept in a range around a reference level, so called Normal Navigation Level (NNL). The water level has to be maintained in the navigation range in order for the reach to be operable.

The European Union encourages the development of inland navigation network, especially by using ICT technologies [15]. Tele-controlled sensors and actuators can be installed in order to establish constant on-line monitoring of the system $[44,16]$ by using SCADA (Supervisory Control and Data Acquisition) systems. The collected historical data can be used to study the navigation reach. There are SCADA systems specially developed for inland navigation [7, 23]. The navigation system can benefit from the use of the SCADA from the maintenance and also from the security point of view [2]. Additionally, there are simulation tools specially developed for inland navigation systems [1].

Another big challenge for the inland navigation networks in the future is the effects of the climate change. These networks are very vulnerable to the climate change [6]. Different climate models are available from 10 to 100 years from the literature [36]. Some of these models include the other effects like farming [18] or social and economic aspects [10]. The effects of climate change are also studied regionally, for example in the French river basins: $[5,11]$, Mediterranean basin in [17], basins in U.K. [24], [3] and China [52], U.S. [35]. The different studies share some possible effects: global rise of mean sea level, increase in the occurrence of extreme weather events, increase in the surface temperature of the water and changes in river morphology. These events cause changes in water supply and quality that can lead to stronger constraints for inland navigation.

On some navigation systems the effect of climate change is already studied. In the great lakes the climate change can result in lower water levels and shorter ice cover. While due to the first factor the vessel load should be reduced (negative effect) due to the second the navigation period can be extended (positive effect). As to adaptive measures intensified dredging and shift of transport to rail is predicted [35]. In Northern Europe studies also describe the decrease in water level. As adaptation similar measures are proposed, but only a modest modal shift to rail is mentioned [25]. The ECCONET European projects studied the effect of climate change on the Middle Rhine, Upper Danube and the Rhine-Main-Danube corridor. For the middle of 21st century the frequency of low flow situations are likely to increase only in the Upper Danube, however, for the distant future low flow situations will become more frequent in all the studied area. They emphasize the regional differences of the behavior [6] .

From these conclusions it can be seen that each system is different, as the regional effects of the climate change also differ in great extent. 


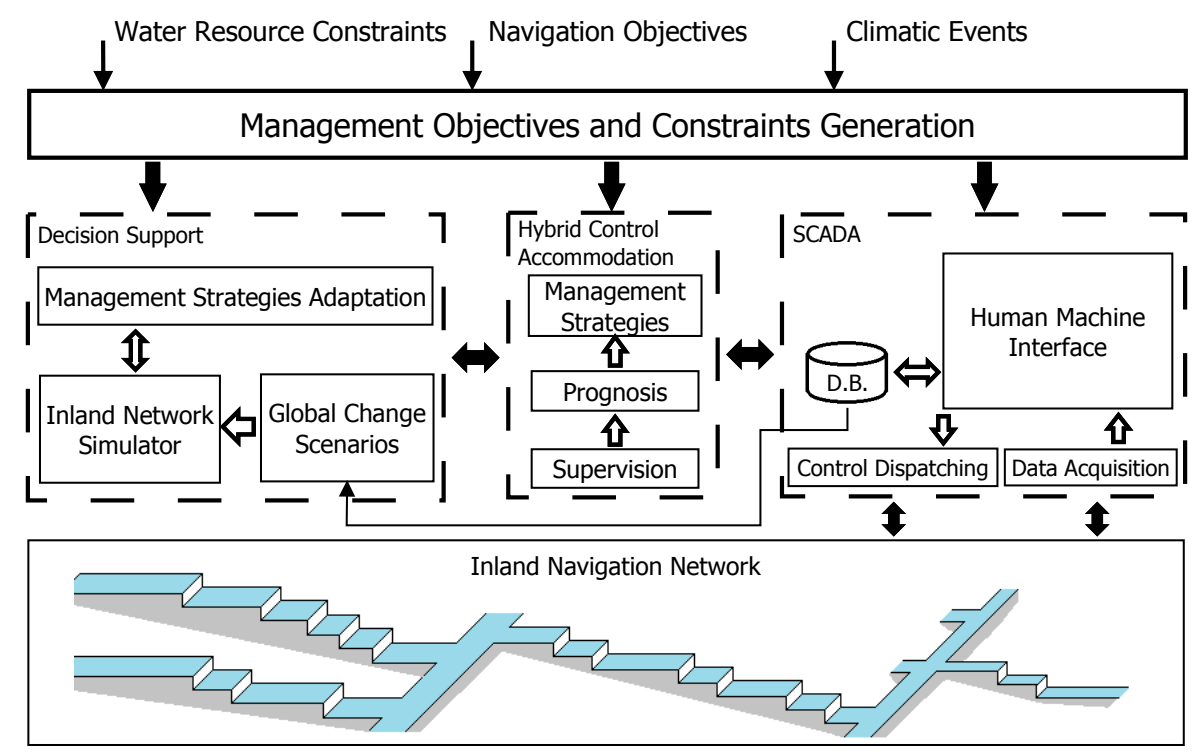

Fig. 1 The schematics of the global modelling approach.

The GEPET-Eau project [14] addresses the abbreviation of adaptive and predictive management strategies for inland navigation networks. The global management architecture is shown in Figure 1 [13]. This architecture is based on a SCADA (Supervisory Control And Data Acquisition) system which allows the tele-management of the network. The management rules and the constraints on the water uses are regrouped in the Management Objectives and Constraints Generation module. Depending on these rules, the Hybrid Control Accommodation module allows the determination of the setpoints that have to be sent to the actuators of the system according to its current state and the forecast of the flood events and the drought periods. The management strategies are adapted taking into account new extremes events. Thus, the long term control objective is to make navigation possible in different external conditions: in case of floods when there is excess of water and the water system should be operated in a way to let the flood wave pass without inundating the neighboring cities. In case of drought, there is a lack of water, and first it should be supplied to priority purposes (link drinking water) and then to navigation. By modeling the global system and extending the controls strategy the final goal of the project is to give solutions for navigation for different scenarios in a global change context. Therefore the goal of the GEPETEau project is to study the effect and the adaption to climate change of the navigation network of the north of France.

In order to understand and predict or control the system modeling is needed. The open channel flow is governed by a pair of hyperbolic partial differential equations, 
the Saint-Venant (SV) equations. These equations have no analytical solution for every case, therefore in practice numerical solutions are used. Due to the nonlinearity of these equations, for controller development simplified versions of the SV equations [30] or simple models deduced from these equations are used [29, 28, 42].

Model predictive control (MPC) is commonly used to control different type of water systems, and [37, 41, 38, 50]. Using an internal model it is able to incorporate the response characteristics of the system to the control actions, and most importantly it is able to deal with constraints on the control or controlled variables. This ability is especially useful when it is applied to navigation systems. The goal for navigation systems is to maintain the water level as close as possible to a certain level, but definitely stay within a certain range. To achieve this hard constraints of MPC can be used. Often there are constraints on the input: the artificial navigation reaches are filled from natural resources, whose availability is restricted. This Cuinchy-Fontinettes Reach (CFR) case study is an example for this case.

A large scale model of the CFR is developed based on physical rules and system identification approaches [13]. Smaller time and space scale gray box model has been developed in [12] and improved in [21]. This model has been used for controlling the water level in the reach [4] and also for sensor [40] and actuator [39] fault detection.

The goal of this work is by using ICT and control techniques to obtain the best performance of the transport of a canal reach bounded by locks. There is a dynamic connection between the water and the transport system and this connection is bidirectional. The main goal of the study of the transport of water is to allow the transport over water. The water movement should be modeled and controlled in order to maintain the normal navigation level to allow the boats safely navigating. The connection also exists in the other direction: in order to allow navigation lock operations are carried out, that is water is transported (Figure 2).

As in case of a canal reach bounded by locks, lock operations control the transport flow and also the water flow. In this work, lock operations are not controlled, the water flow is only controlled through the surrounding hydraulic structures and the lock operations are treated as disturbance. The control of inflow influences the transport flow: if the water level is not maintained high enough the lock operations would cause a disturbance in the water level out of the range of the allowed water level. Therefore the control of the hydraulic structures and water levels control the interactions between water and transport flow and hence indirectly the transport flow.

This chapter is structured as follows: first the general modeling is described then the case study in introduced. After the application of the model to the case study is presented, the results are shown. Then the impact of this work within the framework of transport of and over water is explained. Finally, conclusions are drawn and some open questions are raised. 


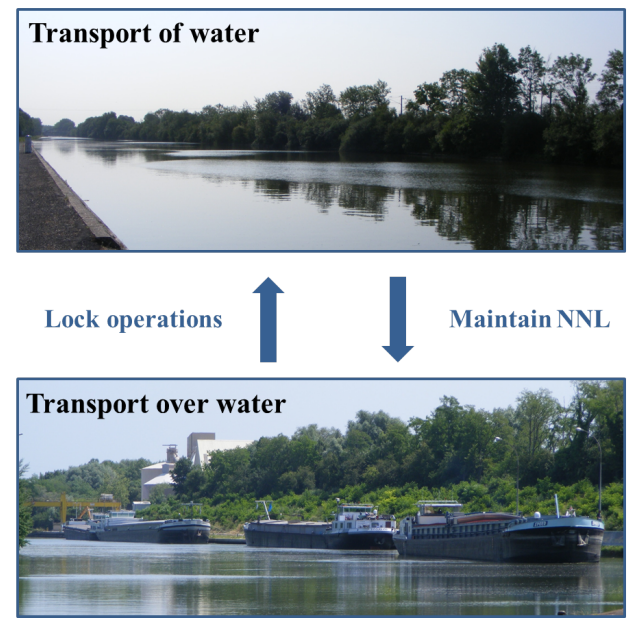

Fig. 2 The interaction between transport of water and transport over water in the case of navigation canals.

\section{Methodology: modeling the reach for control purposes}

In order to model the canal reach for control purposes the Integrator Delay Zero (IDZ) model [28] was used. The model is an extension of the Integrator Delay (ID) model [42], that is commonly used in MPC [51, 47].

The ID model captures two governing phenomena of a canal reach: the low frequency integrator behavior and the time delay. The IDZ model includes a zero in order to approximate better the high frequency behavior.

At low frequencies the canal reach behaves as a tank: the water volume is the integral value of the difference between the inflow and the outflow. The water level is proportional to the water volume and the constant of this proportion is the water surface, often called backwater area, $A_{s}$ (of course, supposing it to be constant is a simplification of the geometry):

$$
A_{s}^{0}=B^{0} L
$$

where $B$ is the average cross sectional width (for rectangular canals) and $L$ is the length of the canal reach. The upper case zero indicates that the variables are calculated for a certain steady state regime.

The time delay expresses the time between a change occurring at one extreme of the canal reach and this change can be observed in the other extreme. It depends mainly on the velocity of a traveling wave (celerity) and the length of the canal reach. It is slightly different in the upstream $\left(\tau_{u}\right)$ and in the downstream direction $\left(\tau_{d}\right)$ and it can be obtained as:

$$
\tau_{u}^{0}=\frac{L}{C^{0}-V^{0}}
$$


and

$$
\tau_{d}^{0}=\frac{L}{C^{0}+V^{0}}
$$

where $V$ is the velocity and $C$ is the celerity:

$$
C^{0}=\sqrt{g H^{0}}
$$

and

$$
V^{0}=\frac{Q^{0}}{H^{0} B^{0}}
$$

where $g$ is the acceleration of gravity, $H$ is the water depth.

A zero is added to the ID model in order to account for the high frequency behavior. When a change occurs, (e.g. a discharge step) the first fast increase in water level is modeled very well with the IDZ model due to the presence of the zero. The IDZ model can be obtained from the geometrical characteristics of the canal reach. Details about the calculation of the model parameters can be found in [28] and [27]. The model is a linear model, therefore the quantities to calcualte the model should be linearized around an equilibrium regime. This variables of the equilibrium regime are indicated with an uppercase zero.

The final structure of the IDZ model is the following:

$$
G(s)=\frac{p_{1}^{0} s+1}{A_{s}^{0} s} e^{-\tau^{0} s},
$$

where the parameter $p_{1}$ accounts for the zero and $\tau$ can be $\tau_{u}$ in the upstream direction and $\tau_{d}$ in the downstream direction. $G(s)$ is the transfer function between the input discharge (upstream or downstream) and the water level (upstream or downstream).

\section{Case study}

The navigation system of the north of France allows the transport of goods from Paris to the port of Dunkerque and to Belgium (Figure 3). The system consists of three watersheds: the Aa, the Lys and the Scarpe. Navigation canals are artificial water bodies and usually perpendicular to the natural runoff of the watersheds. Due to the changes in the relief, the canal reaches are connected with locks to overcome the difference in altitude (Figure 4). The Cuinchy-Fontinettes reach (CFR) is located in the centre of the network. The water flows feeding the reach are shown in Figure 5. The upstream part between Cuinchy to Aire-sur-la-Lys is $28.7 \mathrm{~km}$ long and called 'canal d'Aire', the downstream part between Aire-sur-la-Lys to Saint-Omer is $13.6 \mathrm{~km}$ long and called 'canal de Neuffossé'. The overall length is $42.3 \mathrm{~km}$ and the CFR is bounded by the lock of Cuinhy (upstream) and the lock of Fontinettes (downstream). At Aire-sur-la-Lys there is the confluence of the river Lys divided by 


\begin{tabular}{ccccc}
\hline $\begin{array}{c}\text { Length } \\
(\mathbf{m})\end{array}$ & $\begin{array}{c}\text { Width Depth Manning's c. Discharge } \\
(\mathbf{m})\end{array}$ & $\begin{array}{c}\text { (m) } \\
\mathbf{m}^{\mathbf{3}} / \mathbf{s}\end{array}$ \\
\hline 42300 & 52 & 3.8 & 0.035 & 0.6 \\
\hline \hline
\end{tabular}

Table 1 Physical data of the CFR.

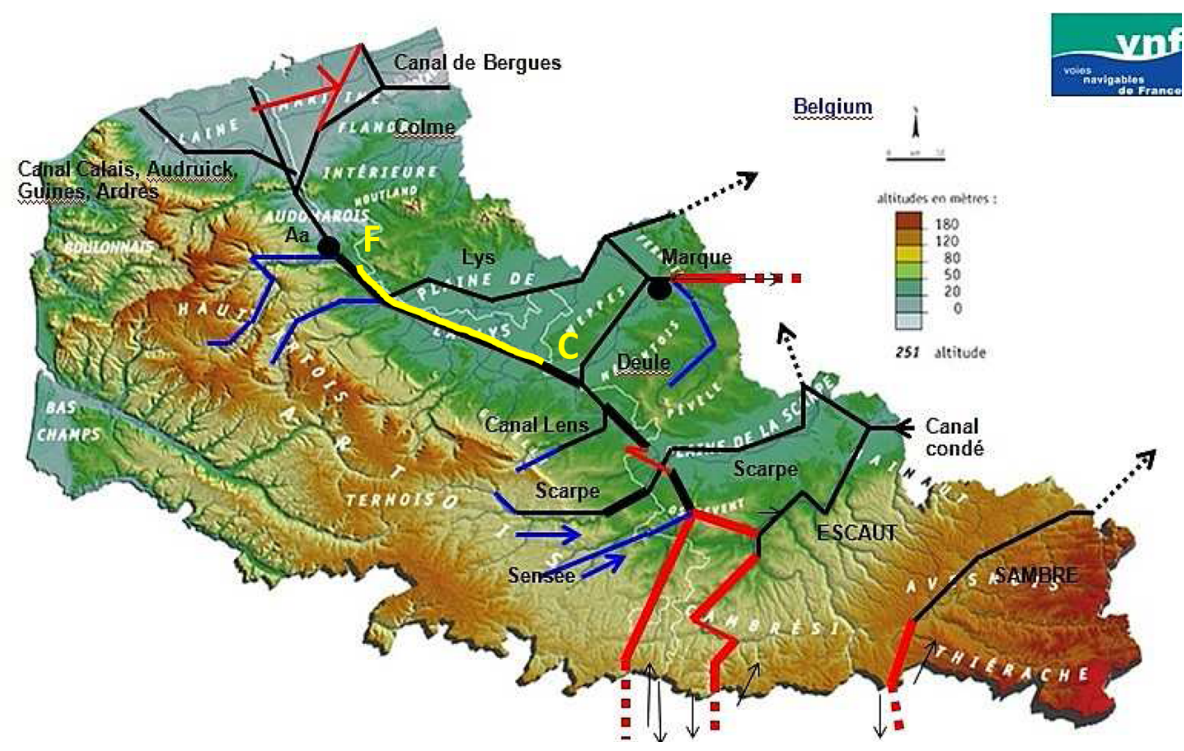

Fig. 3 Navigation canal system of the north of France, the CFR is highlighted with yellow and the location of the locks is indicated with yellow, the yellow $\mathrm{C}$ shows the location of lock Cuinchy, and the $\mathrm{F}$ of the location of lock Fontinettes.

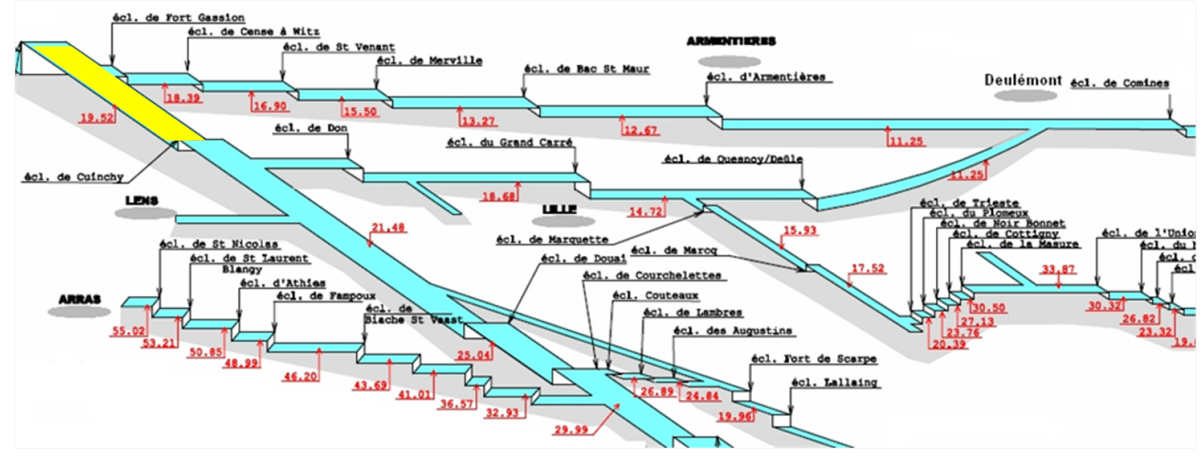

Fig. 4 The Nornal Navigation Levels of the canal system (red color) and the corresponding locks (black color), the CFR is highlighted with yellow.

a sluice gate from the CFR. The CFR is approximately $52 m$ wide, it is entirely artificial without considerable slope. The geometry of the reach and the chosen steady state regime for linearization is summarized in Table 1. 


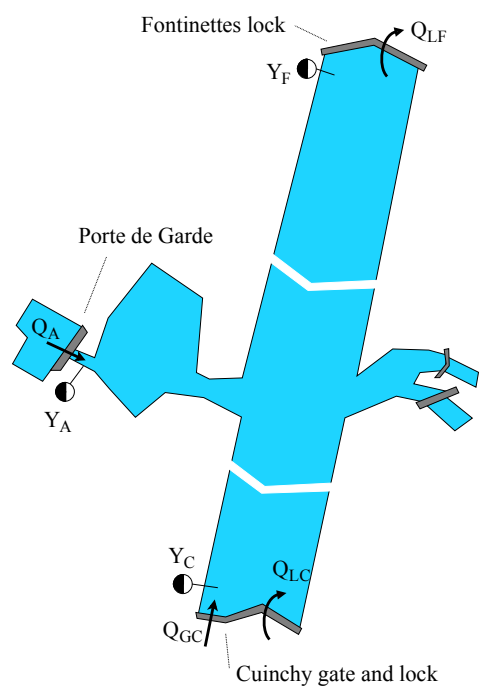

Fig. 5 The Cuninchy-Fontinettes reach, $Q_{L C}$ is the discharge of lock Cuinchy, $Q_{G C}$ is the discharge of the gate of Cuinchy, $Q_{A}$ is the discharge of the gate of Aire and $Q_{F}$ is the discharge of lock Fontinettes. $Y$ indicates the corresponding water levels.

The lock of Cuinchy overcomes a difference of $2 m$ between the upstream and downstream water levels, its volume is $3700 \mathrm{~m}^{3}$. The maximum discharge that supplies or empties the lock chamber is $11 \mathrm{~m}^{3} / \mathrm{s}$. The lock of Fontinettes has several times bigger volume, $25000 \mathrm{~m}^{3}$, as it overcomes $13 \mathrm{~m}$ of water level difference. The maximum discharge it is supplied with is $28 \mathrm{~m}^{3} / \mathrm{s}$. When a lock is operated the chamber is supplied from the upstream reach and emptied downstream. Hence the operation of lock Cuinchy supplied the CFR and the operation of Fontinettes empties the CFR.

The main control objective is to ensure navigation, that is maintain the water level in a range around the Normal Navigation Level (NNL). In case of the CFR, it is $N N L=19.52 m N G F$ (Nivellement Général de la France, i.e. altitude landmark in France). In order to do thism whenever a lock operation occurs. hydraulic structures are set in to maintain the water levels. These structures are remotely controlled, usually manually, using the water level and discharge measurements.

There are three possible locations with control structures in the CFR (Figure 5):

- At Cuinchy: a lock and a gate which are located side by side,

- At Aire-sur-la-Lys: the gate called 'Porte de Garde',

- At Fontinettes: a lock.

The water level fluctuation is basically caused by the lock operations. Figure 6 shows the measured water levels at the lock of Cuinchy and at the lock of Fontinettes and at Aire. It can be seen that a lock operation of Fontinettes causes a drop in the water level of more than $20 \mathrm{~cm}$. With gray dashed line the minimum of the future 


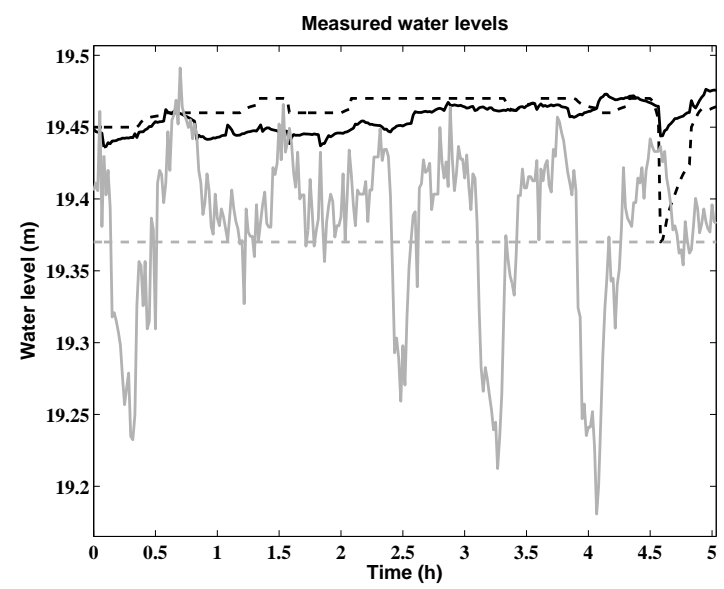

Fig. 6 Measured water levels; Cuinchy: black dashed line, Aire: black continuous line, Fontinettes: gray continuous line.

navigation range is shown. It can be seen that in the future the disturbance caused by such lock operation is not allowed, the control of water level should be improved. A wave caused by a lock operation can travel back and forth several times before it attenuates; this is seen by the smaller secondary valleys coming back in approximately 4 hours after a lock operation ("big valley"). Figure 7 shows the water levels after only one lock operation of Fontinettes (numerical simulation). It can be seen that after the first drop of $17 \mathrm{~cm}$ the negative wave comes back in 4 hours and causes a drop of $10 \mathrm{~cm}$, and in every 4 hours causing consecutive drops in the water level at Fontinettes (with gray). The drops can be seen in the other water levels measured at Cuinchy and Aire - at Cuinchy (with black) the negative wave appears after two hours, this is the time delay of the system. This phenomenon is called resonance and it is first described in [43] and [46], and later studied in depth in [49] and [48].

These waves without control can cause the water levels go out of the allowed range of navigation. In order to maintain the reach in a condition to be possible to navigate the lock operations should be changed or the hydraulic structures should be operated in a way to counterbalance the act of the waves generated by the locks. In this work the second option is addressed with the help of MPC. By implementing a MPC controller to the hydraulic structures and controlling the water supply of the navigation reach it could be possible to maintain the water levels within the navigation range. 


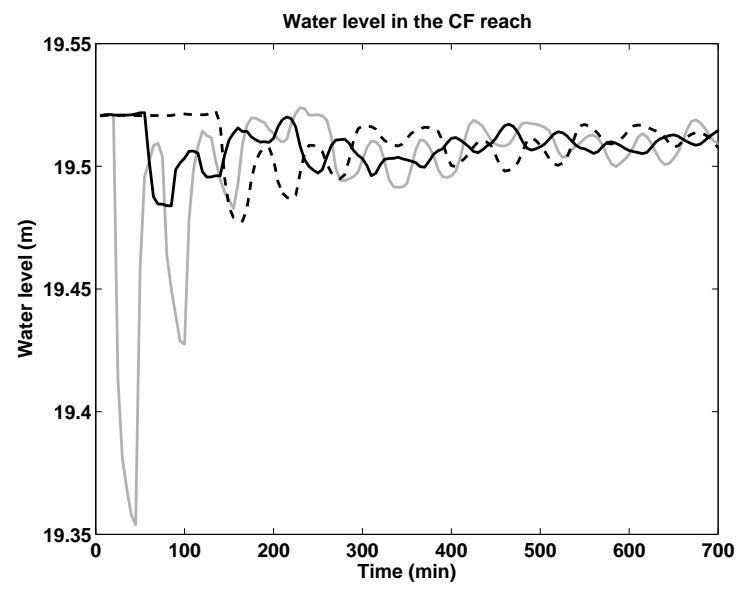

Fig. 7 Simulation of one lock operation of Fontinettes; Cuinchy: black dashed line, Aire: black continuous line, Fontinettes: gray continuous line.

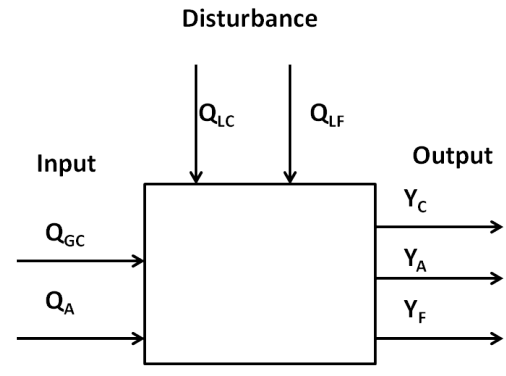

Fig. 8 The schematics of the CFR system.

\subsection{Application of the IDZ model to the CFR}

The CFR system has two inputs (flows) and three outputs (water levels). Also, there are two disturbance flows (lock operations), that are not modeled in this case. As it is shown in Figure 5 the water levels are measured and to be controlled at three locations: at upstream - at Cuinchy $\left(Y_{C}\right)$, in the middle of the reach - at Aire $\left(Y_{A}\right)$ and at downstream - at Fontinettes $\left(Y_{F}\right)$. These water levels are disturbed by the lock operations upstream by the lock Cuincy - $Q_{L C}$ and downstream by lock Fontinettes $\left(Q_{L F}\right)$. These lock operations are unknown for the controller.

If both locks are operated in the same frequency a considerable amount of water is removed from the system since the volume of the lock of Fontinettes is five times bigger than the volume of the lock of Cuinchy. In order to maintain the water level the water volume should be added. It is possible from two control points: upstream, from the gate of Cuinchy $\left(Q_{G C}\right)$ and in the middle of the reach, from the gate of Aire $\left(Q_{A}\right)$. Both of these flows have physical constraints: at Cuinchy the maximum 


\begin{tabular}{cccc}
\hline \hline Name & $\begin{array}{l}\text { Backwater } \\
\text { surface }\left(\mathbf{m}^{\mathbf{2}}\right)\end{array}$ & $\begin{array}{c}\tau \\
(\mathbf{s})\end{array}$ & $\begin{array}{c}p_{1} \\
(-)\end{array}$ \\
\hline$G_{C C}$ & $1492 \times 10^{3}$ & 0 & 9401 \\
$G_{A C}$ & $1492 \times 10^{3}$ & 4703 & 4618 \\
$G_{C A}$ & $1492 \times 10^{3}$ & 4698 & 4618 \\
$G_{A A}$ & $1492 \times 10^{3}$ & 0 & 9238 \\
$G_{C F}$ & $2100 \times 10^{3}$ & 6925 & 6749 \\
$G_{A F}$ & $707 \times 10^{3}$ & 2226 & 2209 \\
\hline \hline
\end{tabular}

Table 2 Properties of the three reaches.

flow is $10 \mathrm{~m}^{3} / \mathrm{s}$ and no negative flow is possible, while at Aire the flow can fluctuate between -7 and $+7 m^{3} / \mathrm{s}$. MPC can handle very well such constrained systems. Each transfer function of the CFR system is modelled by the IDZ model. The scheme of the system is shown in Figure 8. All transfer functions are obtained by linearizion around an equilibrium point: $Q_{A}^{0}=0.6 \mathrm{~m}^{3} / \mathrm{s}, Q_{G C}^{0}=0.6 \mathrm{~m}^{3} / \mathrm{s}$ and $Y_{A}^{0}=Y_{C}^{0}=Y_{F}^{0}=$ $N N L=19.52 \mathrm{~m}$, that approximation corresponds to a water depth $(H)$ of $3.8 \mathrm{~m}$ all around the reach due to the zero slope (see also in Table 1). The transfer function of the linearized system is then can be described by a matrix containing six transfer functions:

$$
G_{C F R}=\left(\begin{array}{cc}
G_{C C} & G_{A C} \\
G_{C A} & G_{A A} \\
G_{C F} & G_{A F}
\end{array}\right),
$$

where transfer functions $G_{C C}, G_{A C}, G_{C A}, G_{A A}, G_{C F}, G_{A F}$ have the IDZ structure as in (6). The values of the parameters are summarized in Table 2.

\subsection{Controller development}

MPC was developed based on [8] and [46]. The detailed controller development can be found in [22]. Below we follow the presentation of [22]. That is, the control objective is to keep the outputs $\left(Y_{C}, Y_{A}\right.$ and $\left.Y_{F}\right)$ close to set-point, while disturbances occur $\left(Q_{L C}\right.$ and $\left.Q_{L F}\right)$. This is achieved by controlling the two inputs $\left(Q_{G C}\right.$ and $\left.Q_{A}\right)$, while ensuring that the discharge and Cuinchy and Aire satisfy the physical flow constraints of the system (8) and (9) below.

$$
0 \leq Q_{G C}(t) \leq 10\left[\mathrm{~m}^{3} / \mathrm{s}\right]
$$

and

$$
-7 \leq Q_{A}(t) \leq 7 \quad\left[m^{3} / s\right]
$$

for all $t \in[0,+\infty)$. The transfer functions presented in Section 2 express the relation between the water level and the input/output discharges. In order to be able to apply MPC, we carried out the following steps: 
1. We transform the continuous-time transfer function from (7) to a discrete-time one.

2. Instead of using the upstream discharge as input, we use the change of the discharge as control input. This is incorporated into the discrete-time transfer functions by composing it with an integrator. The reason for the change is that it is easier to express the MPC cost function for this new input than for the original one.

3. We compute the minimal state-space representation of the thus obtained discrettime transfer function.

4. Since MPC yields a state feedback, while the full state of the system is not measurable, we constructed an observer. The controller is then obtained by combining the state feedback provided by MPC with this observer.

The controller was tested by simulating its interconnection with a detailed nonlinear model of the plant. The plant model was implemented in SIC. The model is based on Saint-Venant equations, and it is widely accepted as a fairly accurate representation of physical reality. In particular, it models several non-linear phenomena which are ignored by IDZ type models.

Below we describe the steps mentioned above one by one.

\subsubsection{Sampling the linearized model}

The transfer function $G_{C F R}$ is transformed to a discrete-time transfer function $G_{C F R}^{d}$ using the zero order hold with sampling time $T_{s}=300 \mathrm{~s}$. Hence, if we define the discrete time signals $e(k)=E\left(k T_{s}\right)$ and $Q^{d}(k)=Q\left(k T_{s}\right), k=0,1,2, \ldots$ and we denote their $z$-transforms by $\hat{e}$ and $\hat{Q}^{d}$, respectively, then

$$
\hat{e}=G_{C F R}^{d} \hat{Q}^{d}
$$

holds, where $\hat{e}$ denotes the z-transform of the discrete-time signal $e$ and $\hat{Q}^{d}$ denotes the z-transform of the discrete-time signal $\hat{Q}^{d}$.

\subsubsection{Setting the rate of change of the discharge as input}

The discrete-time transfer functions are multiplied by an integrator $\frac{1}{z-1}$, i.e. we define the transfer matrix

$$
H(z)=G_{F C R}^{d}(z) \frac{1}{z-1}
$$

This is done in order to be able to use the differences between discharges as inputs, as opposed to the discharge. That is, the control input used for MPC control synthesis is the discrete-time signal $u$; such that $u(0)=0$ and

$$
u(k)=Q^{d}(k)-Q^{d}(k-1) .
$$


It then follows that with the transfer function $H(z)$ from (11), $\hat{e}=H \hat{u}$, where $\hat{u}, \hat{e}$ denote th $z$-transforms of $u$ and $e$ respectively.

\subsubsection{Constructing a state-space model}

Using standard MATLAB functions, we compute a minimal state-space representation

$$
\begin{aligned}
& x(k+1)=A x(k)+B u(k) \\
& e(k)=C x(k)
\end{aligned}
$$

of the transfer matrix $H$. In order to formalize the physical constraints on $Q^{d}(k)$, we extend the state-space of (12) by a new state which represents $Q^{d}$. The resulting model is as follows:

$$
\begin{aligned}
& z(k+1)=\tilde{A} z(k)+\tilde{B} u(k) \\
& e(k)=\tilde{C} z(k)
\end{aligned}
$$

where $z(k)=\left[x^{T}(k), Q^{d}(k)\right]^{T}$ and

$$
\begin{aligned}
\tilde{A} & =\left[\begin{array}{ll}
A & 0 \\
0 & I_{2}
\end{array}\right] \quad \tilde{B}=\left[\begin{array}{l}
B \\
I_{2}
\end{array}\right], \\
\tilde{C} & =\left[\begin{array}{ll}
C & 0
\end{array}\right]
\end{aligned}
$$

where $I_{2}$ denotes the $2 \times 2$ identity matrix.

\subsubsection{MPC state feedback}

In order to compute the control law, we use MPC, applied to the state-space representation (13). The resulting state feedback $u(k)=w(z(k))$. The map $w$ is obtained as follows. Set $\lambda=40$ and define the matrices $R=40.000 I_{2}$ and $P=40.000 I_{3}$, where $I_{2}$ and $I_{3}$ are the $2 \times 2$ and $3 \times 3$ identity matrices. The matrices $R$ and $P$ are weights, and $\lambda$ is the prediction horizon. Define

$$
w(z)=u^{*}(k \mid k)
$$

where $u^{*}=\left(u^{*}(k \mid k), u^{*}(k+1 \mid k), \ldots, u^{*}(k+\lambda-1 \mid k)\right)$ is the solution of the following constrained optimization problem: 


$$
\begin{aligned}
& \min _{u=(u(k \mid k), u(k+1 \mid k), \ldots, u(k+\lambda-1 \mid k)) \in \mathbb{R}^{2 \lambda}} J(z, u) \\
& J(z, u)=\sum_{j=1}^{\lambda} e(k+j \mid k)^{T} P e(k+j \mid k) \\
& +\sum_{j=0}^{\lambda-1} u(k+j \mid k)^{T} R u(k+j \mid k)
\end{aligned}
$$

subject to the following constraints:

$$
\begin{aligned}
& z(k \mid k)=z \\
& \forall j=1, \ldots, \lambda: \\
& z(k+j+1 \mid k)=\hat{A} z(k+j \mid k)+\hat{B} u(k+j \mid k) \\
& e(k+j \mid k)=\hat{C} z(k+j \mid k) \\
& 0 \leq z_{n+1}(k+j \mid k) \leq 10\left[\mathrm{~m}^{3} / s\right] \\
& -7 \leq z_{n+2}(k+j \mid k) \leq 7 \quad\left[\mathrm{~m}^{3} / s\right]
\end{aligned}
$$

Here $n$ denotes the size of the state-space of (12), and $z_{i}(k+j \mid k)$ denote the $i$ th entry of $z(k+j \mid k)$. The inequalities (8)-(9) represent physical constraints on the inputs.

In order to solve this optimization problem, we used the built in MATLAB function [33].

\subsubsection{Constructing the observer}

Qpplying MPC to (13) requires the knowledge of the full state $z(k)$ at every step $k$. However, in practice, the full state is not measured. To address this problem, we used an observer to estimate the state $z(k)$. Since the component $Q^{d}(k)$ is clearly observable, we used the following reduced order observer

$$
\begin{aligned}
& \hat{x}(k+1)=A \hat{x}(k)+B u(k)+L(e(k)-C \hat{x}(k)), \quad \hat{x}(0)=0 \\
& \hat{Q}^{d}(k+1)=\hat{Q}^{d}(k)+u(k), \quad \hat{Q}_{d}(0)=0
\end{aligned}
$$

where the matrices $A, B, C$ are the same as in (12) and $L$ is computed as according to synthesis algorithms for minimax observers [9, 26, 19]. More precisely, we consider a noisy state-space representation

$$
\begin{aligned}
& x(k+1)=A x(k)+B u(k)+\eta(k) \\
& e(k)=C x(k)+v(k)
\end{aligned}
$$

where $\eta$ and $v$ are deterministic noise processes satisfying

$$
\sum_{k=0}^{\infty}\left(\eta^{T}(k) W_{1} \eta(k)+v^{T}(k) W_{2} v(k)\right) \leq 1,
$$


with $W_{1}=\left(1000 * I_{n}+5000 e_{1} e_{1}^{T}\right)^{-1}, W_{2}=I_{3}, n$ is the dimension of the state-space of (12), $I_{n}, I_{2}$ are the $n \times n$ and $2 \times 2$ identity matrices, $e_{1}=(1,0, \ldots, 0)^{T} \in \mathbb{R}^{n}$. The matrices $W_{1}$ and $W_{2}$ represent our assumptions on the energy of the disturbances $\eta$ and $v$. The larger these matrices are, the smaller the assumed energy of the disturbance. A minimax observer for (17) is a system of the form

$$
\hat{x}(k+1)=A \hat{x}(k)+B u(k)+L(e(k)-C \hat{x}(k))
$$

such that the worst case estimation error $\lim \sup _{k \rightarrow \infty} \sup _{v, \eta}\left|l^{T}(x(k)-\hat{x}(k))\right|$ is minimal for any vector $l \in \mathbb{R}^{n}$, where the the supremum is taken over all signals $v$ and $\eta$ which satisfy (18). The gain matrix $L$ is obtained following $[9,26,19]$. That is, we consider the dual LQR control problem

$$
\begin{aligned}
& \min _{v} \sum_{k=0}^{\infty}\left(s(k)^{T} W_{1}^{-1} s(k)+v^{T}(k) W_{2}^{-1} v(k)\right) \\
& s(k+1)=A^{T} s(k)+C^{T} v(k) .
\end{aligned}
$$

Note that due to minimality of (12), $(C, A)$ is an observable pair, and hence $\left(A^{T}, C^{T}\right)$ is a controllable pair. From this it then follows that the LQR control problem (20) has a solution of the form $v=-K s$. In addition, the matrix $\left(A^{T}-C^{T} K\right)$ of the closeloop system is stable. We then set $L=K^{T}$ to be the gain of the minimax observer (19).

Note that if the linear model $H$ had been accurate and the disturbances had not been significant, then any choice of $L$ such that $(A-L C)$ is stable could have been considered. In fact, we tried to use pole placement to obtain such an $L$. However, when interconnected with the nonlinear numerical model of the system, the observers obtained in such a way showed worse performance than the minimax observer. This is probably due to the fact that our model is just a crude approximation of the underlying physical process, moreover, it does not explicitely include all the disturbances which act on the system.

\subsubsection{Control architecture}

The MPC controller was connected with the observer (16): when computing the next control input $u(k)$, the estimates $\hat{x}(k)$ and $\hat{Q}^{d}(k)$ of the observer (16) were used instead of $z(k)$. Due to our modelling choices, the true control input which is ought to be applied to the physical system is not $u(k)$, but $Q^{d}(k)+Q^{0}$, where $Q^{0}=\left(Q_{G C}^{0}, Q_{A}^{0}\right)=(0.6,0.6)^{T}$ is the stead-state input corresponding the set point $(N N L, N N L, N N L)^{T}$. Likewise, the actual measurements are the the values $Y_{C}\left(k T_{s}\right)$, $Y_{A}\left(k T_{S}\right)$ and $Y_{F}\left(s T_{S}\right)$, not the error signal $e(k)$. The latter can be obtained from the former by substracting the value of NNL.

To sum up, if we denote by

$$
y(k)=\left[Y_{C}\left(k T_{S}\right), Y_{A}\left(k T_{S}\right) Y_{F}\left(k T_{S}\right)\right]^{T} \forall k=0,1, \ldots
$$


the sampled measurement signals, then the equations of the controller can be summarized as follows:

$$
\begin{aligned}
& e(k)=y(k)-[N N L, N N L, N N L] \\
& u(k)=w\left(\left[\hat{x}^{T}(k) \hat{Q}^{d}(k)\right]^{T}\right) \\
& \hat{x}(k+1)=A \hat{x}(k)+B u(k)+L(e(k)-C \hat{x}(k)) \hat{x}(0)=0 \\
& \hat{Q}^{d}(k+1)=\hat{Q}^{d}(k)+u(k) \hat{Q}_{d}(0)=0 \\
& Q^{d}(k)=\hat{Q}^{d}(k)+u(k)+Q^{0}
\end{aligned}
$$

where $w$ is the same as define in (14), the gain $L$ is as in (16), the matrices $A, B, C$ are from (12).

\subsubsection{Evaluation of the performance}

The performance of the controller was evaluated as follows. First, we built a numerical model of the CFR was built using the SIC (Simulation of Irrigation Canals) [31]. The controller (with partial observations) was tested by connecting it with the nonlinear model of SIC and carrying out simulations. Note that SIC simulates the behavior of the system in continuous time, so we had to perform time sampling of the output and input signals: while performing the simulation, $y(k)$ was set to be the output of the simulation at the $k$ th sampling time, and the control input was taken to be constant between the sampling times.

\section{Results and discussion}

The developed controllers were tested on a numerical model, solving the complete set of non-linear Saint-Venant equations using a finite differences scheme. The solution was implemented by the SIC (Simulation of Irrigation Canals) [31] software. The controllers were developed in Matlab [33] environment. The SIC calls the control algorithm and sends the measurements to it at control time step and executes its commands.

The MPC was tested using the following scenario: 20 lock operations of lock of Cuinchy and lock of Fontinettes (Figure 9). This is more difficult than the actual scenario: nowadays there is navigation only during the day. However, the future plan of the management is to extend the navigation period. The water levels resulting from the lock operations without using any control action (constant input discharges at the gate of Cuinchy and gate of Aire) were shown in Figure 10. It can be seen the the water levels are not kept in the allowed range for navigation.

For the same scenario MPC was applied. Figure 11 shows that all the three water levels are within the navigation range, thus the controller accomplished its objective. 


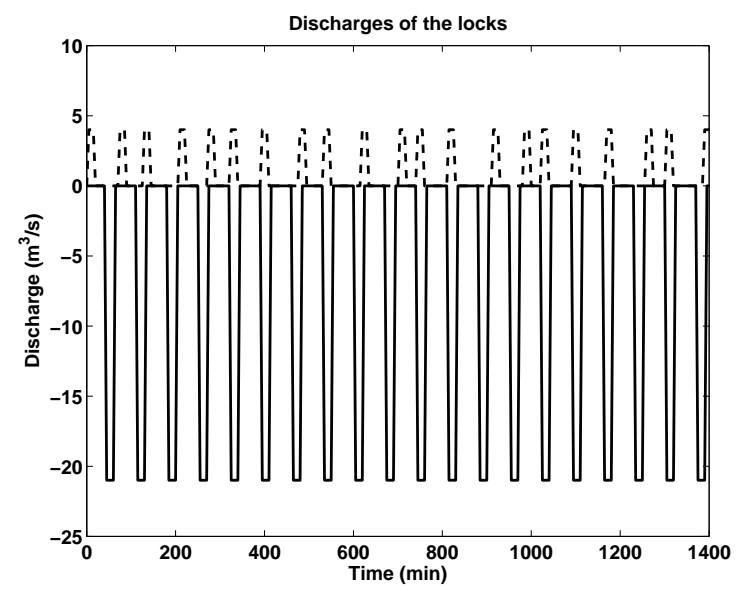

Fig. 9 The discharges of the lock operations during a day with 20 minutes operations, dashed line lock Cuinchy with black line Fontinettes.

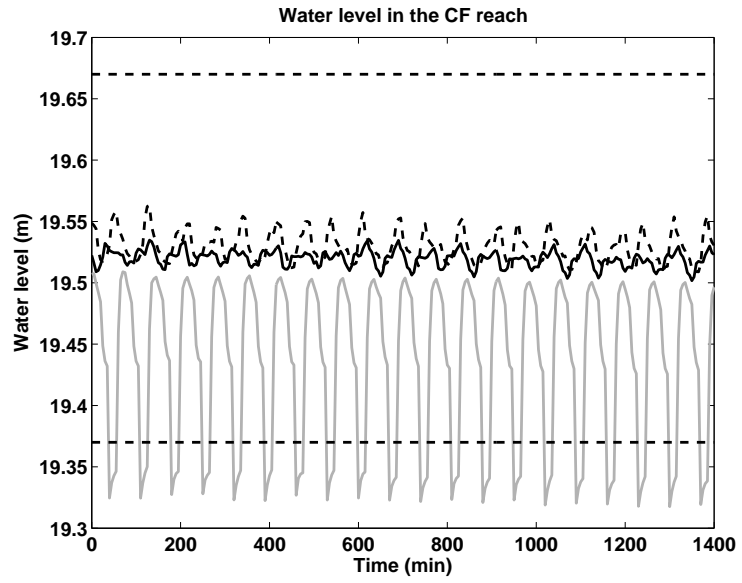

Fig. 10 Simulation of 20 lock operations of Fontinettes and Cuinchy: Cuinchy: black dashed line, Aire: black continuous line, Fontinettes: gray continuous line.

Figure 12 shows the control actions. It is seen that the control flow at Cuinchy is between 0 and $10 \mathrm{~m}^{3} / \mathrm{s}$ and the control flow of Aire fluctuates between $-7 \mathrm{~m}^{3} / \mathrm{s}$ and $+7 \mathrm{~m}^{3} / \mathrm{s}$. Both of them are in the allowed range. The fluctuation might seem high frequency leading to wear and tear, however, in fact the time of one gate opening or closing is 25 minutes. The operations are needed to maintain the water levels. A compromise might be found between the extent of the movement of the hydraulic structures and the desired water level difference between the actual and the desired one. 


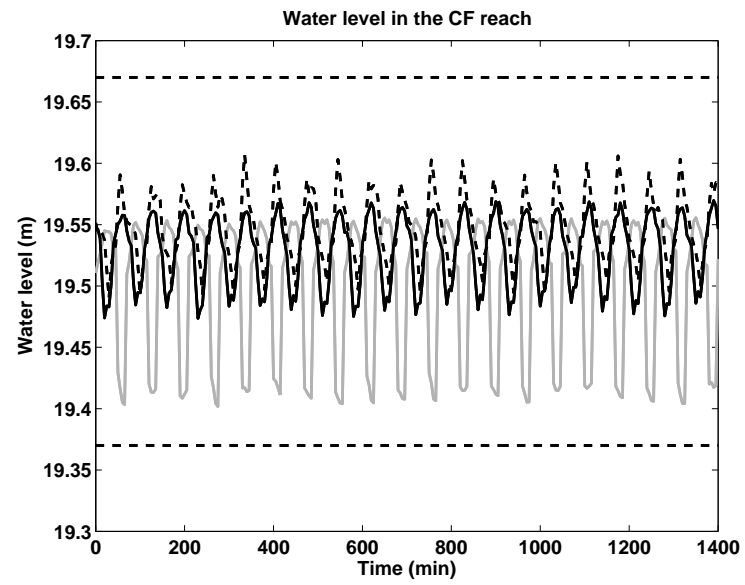

Fig. 11 Controlled levels with MPC, with gray: Fontinettes, with black: Aire and with dashed line Cuinchy, horizontal dashed black line: sea-worthiness condition.

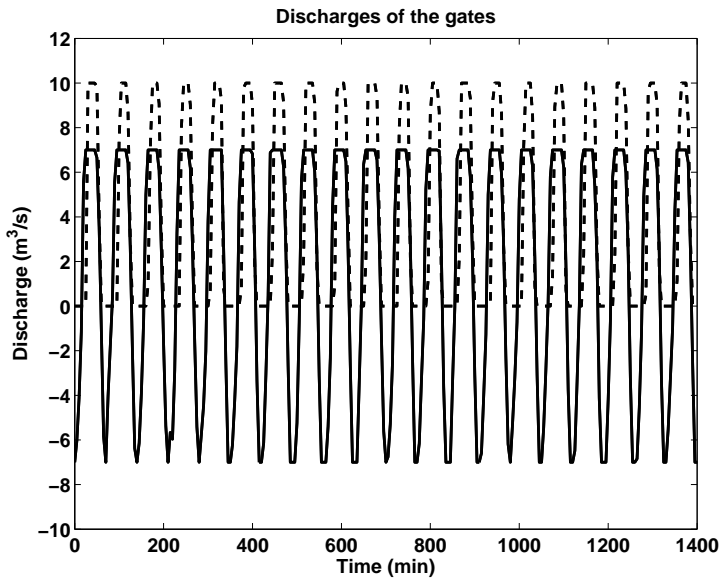

Fig. 12 The control flows with MPC, black line: gate of Aire, dashed line: gate of Cuinchy.

\section{Linking transport of and transport over water}

Large and small scale water transport models are introduced above. In a navigation reach, the transport of water: the inputs and the outputs are completely controlled. The quantity of the runoff arriving directly is often smaller compared to the water released the the lock operations. Hence, therefore all main inputs are locks and the tributaries: connected by hydraulic structures and the operation of the locks. The main transport of water is hence determined by the navigation: by the operation of the locks. The other inputs and outputs are controlled in a way to maintain constant 
volume (that is constant water level). The more lock operations are carried out per day the bigger amount of water has to be transported by the canal reach. However, in case of risk of flood the safety, i.e. flood protection overrules the navigation goals. In this case water is transported, distributed through the system in order to avoid the flood in the cities located near to canal reaches. The nearby river can be evacuated into the navigation canal, and the flood wave can be sent to the sea. In this case the lock operation and hence the traffic is restricted.

The transport over water in this work is presented by the lock operations. The number of daily lock operations correspond to the daily transport of boats. In one lock operation one or two boats can go simultaneously. When a boat is crossing the reach it involves two lock operations: upstream, that results in an increase (for Cuinchy it is $3700 \mathrm{~m}^{3}$ ) of water volume and the downstream operation that results in an offtake (for Fontinettes it is $25000 \mathrm{~m}^{3}$ ). Due to the difference between these volumes any pair of lock operations should be compensated by additional inflows in order to keep the water level constant.

Due to the above described two directional connection between transport of and over water the only way to study the system is the combined framework.

A global modeling and optimization of the operation of the system is beneficial for both the water body (for the cities around this area) and for the users of the canal for transport.

Better global management improves the flood protection of the area. With the help of a global model in case of flood, the flood wave can be distributed in the system and the flooding of the neighboring cities can be avoided. With a better flood protocol and faster response to the floods also the navigation period can be extended.

By better management and control of the water level more lock operations can be carried out while the water level is maintained around NNL. More lock operations allow bigger traffic, that is economical benefit for the operators and also a general ecological benefit as more overland traffic is diverted to navigation.

\section{Open topics and possible future research lines}

The developed MPC can be improved by modeling directly the resonance phenomenon [50, 20]. In this way the controller can directly act on the resonance waves and this might improve the performance. Another possibility to improve the controller performance is to treat the lock operations as known disturbances. That is, if the schedule of the lock operations is known beforehand the controller can act in advance.

By modeling the lock operation the transport is modeled. However, the direct quantitative benefit from the increase of the transport is not modeled yet. Similar models are published [6] for general cases. The cost of lock operations, pumping and the benefit from the transport can be modeled. With the help of this model the effects of the climate change can be directly quantified with relation to the naviga- 
tion system. Similar calculations have been carried out in the project ECCONET [6].

Extending further this line, the cost of each lock operation can be determined based on the economic model. The constantly changing prices and conditions can also be communicated on-line to the stake holders as an addition to the already existing on-line communication about the state of the network and the water levels [45].

Next to the economic perspective the ecologic aspect can also be investigated. Though the navigation network is manly artificial water body, its operation affects the environment and the nearby (confluences) natural water bodies. The effect of the increasing transport to the water quality of the tributaries and to the surrounding flora and fauna can be studied.

As started in this work, the fault detection study can be extended. Not only sensor but also actuator faults should be easily detected. Also the resilience of the system to faults should be investigated and backup plans for sensor faults should be developed.

\section{Conclusions and future research}

The management of navigation canal system can highly benefit of ICT. In order to accomplish the multi-objective goals large and small scale optimization can be applied. Dynamic models can be built being able to predict the reaction of the system of the changes in the future either in operation of the system or of changes of external factors, like climate change. In this work a navigation reach is modelled and based on that MPC is developed to control the water levels in order to keep the water levels in a range to allow navigation. A global volume model of the system is introduced in order to be predict the effects of the long term changes. For different purposes different scale models can be used. Finally by connecting the multi-level models a global model for global management optimization can be achieved. Further research is to include more factors in the optimization like ecology and economy. By modeling the transport (the boats and the lock operation) a model for transport over water can be obtained. By linking the two models, the economical factors can be more directly modeled and predicted.

Acknowledgements This work is a contribution to the GEPET-Eau project which is granted by the French ministery MEDDE - GICC, the French institution ORNERC and the DGITM.

\section{References}

1. O. A. Almaz and T. Altiok. Simulation modeling of the vessel traffic in Delaware River: Impact of deepening on port performance. Simulation Modelling Practice and Theory, 22(0):146 $-165,2012$. 
2. S. Amin, X. Litrico, S. Sastry, and A. M. Bayen. Cyber security of water scada systems - part i: Analysis and experimentation of stealthy deception attacks. IEEE Trans. Contr. Sys. Techn., 21(5):1963-1970, 2013.

3. B. P. Arkell and G. J. C. Darch. Impact of climate change on London's transport network. Proceedings of the ICE-Municipal Engineer, 159(4):231-237, 2006.

4. J. Blesa, E. Duviella, M. Sayed-Mouchaweh, V. Puig, and K. Chuquet. Automatic control to improve the seaworthiness conditions in inland navigation networks. Journal of Maritime Research, 9(3):61-66, 2012.

5. J. Bo, L. Terray, E. Martin, and F. Habets. Projected changes in components of the hydrological cycle in French river basins during the 21 st century. Water Resources Research, 45(8):231237, 2009.

6. T. Breemersch and C. Heyndrickx. Effects of climate change on inland waterway transport networks. In Second Nordic International Conference on Climate change adaptation, Helsinki, Finland, August 29-30. 2012.

7. V. Bugarski, T. Bačkalić, and U. Kuzmanov. Fuzzy decision support system for ship lock control. Expert Systems with Applications, 40(10):3953 - 3960, 2013.

8. Eduardo Fernandez Camacho and Carlos Bordons Alba. Model predictive control. Springer, London, 1998.

9. Felix L Cernusko. State estimation for dynamic systems. CRC Press, 1994.

10. E. G. R. Davies and S. P. Simonovic. Global water resources modeling with an integrated model of the social-economic-environmental system. Advances in Water Resources, 34(6):684-700, 2011.

11. A. Ducharne, F. Habets, C. Pagé, E. Sauquet, P. Viennot, M. Déqué, S. Gascoin, A. Hachour, E. Martin, and L. Oudin. Climate change impacts on water resources and hydrological extremes in northern France. In Proceedings of XVIII International Conference on Water Resources, Barcelona, 2010.

12. E. Duviella, J. Blesa, L. Bako, Y. Bolea, M. Sayed-Mouchaweh, V. Puig, and K. Chuquet. Inland navigation channel model: Application to the Cuinchy-Fontinettes reach. In The 10th IEEE International Conference on Networking, Sensing and Control, Paris, France, April 1012. 2013.

13. E. Duviella, L. Rajaoarisoa, J. Blesa, and K. Chuquet. Adaptive and predictive control architecture of inland navigation networks in a global change context: application to the CuinchyFontinettes reach. In IFAC Conference on Manufacturing Modelling, Management, and Control, Saint Petersburg, Russia, June 19-21. 2013.

14. Duviella E. The GEPET-Eau project @ ONLINE, January 2014.

15. European Parliament and Council of the European Union. Directive 2005/44/EC, 2005.

16. M. Fastenbauer, M. Sattler, and G. Schilk. River information services for commercial users in the inland waterway sector. In LINDI 2007. International Symposium on Logistics and Industrial Informatics, 2007., pages 31-36, 2007.

17. J. M. García-Ruiz, J. I. López-Moreno, S. M. Vicente-Serrano, T. Lasanta-Martínez, and S. Beguería. Mediterranean water resources in a global change scenario. Earth-Science Reviews, 105(34): 121 - 139, 2011.

18. N. Graveline, S. Loubier, G. Gleyses, and J.-D. Rinaudo. Impact of farming on water resources: Assessing uncertainty with monte carlo simulations in a global change context. Agricultural Systems, 108(0):29 - 41, 2012.

19. Michael Green and David JN Limebeer. Linear robust control. DoverPublications. com, 2012.

20. K. Horváth. Model predictive control of resonance sensitive irrigation canals. $\mathrm{PhD}$ thesis, Technical University of Catalonia, Barcelona, Spain, 2013.

21. K. Horváth, E. Duviella, J. Blesa, L. Rajaoarisoa, Y. Bolea, V. Puig, and K Chuquet. Gray-box model of inland navigation channel: Application to the Cuinchy-Fontinettes reach. Journal of Intelligent Systems, 2014.

22. K. Horváth, M. Petreczky, L. Rajaoarisoa, E. Duviella, and K. Chuquet. Mpc control of water level in a navigation canal the cuinchy-fontinettes case study. In 13th European Control Conference (ECC), Submitted, 2014. 
23. Ian White Associates. Report for the inland waterways advisory council information and communication technology for the UK's inland waterways. Technical Report MSU-CSE-002, Inland Waterways Advisory Council Information and Communication Technology, 2008.

24. Jan Brooke Environmental Consultant Ltd and Ian White Associates (Navigation) Ltd. Climate change mitigation and adaptation. implications for inland waterways in England and Wales. Technical report, Inland Waterways Advisory Council, 2009.

25. O. Jonkeren, P. Rietveld, J. van Ommeren, and A. te Linde. Climate change and economic consequences for inland waterway transport in europe. Regional Environmental Change, 2013.

26. Arthur J. Krener. Kalman-bucy and minimax filtering. Automatic Control, IEEE Transactions on, 25(2):291-292, Apr 1980.

27. X. Litrico and V. Fromion. Analytical approximation of open-channel flow for controller design. Applied Mathematical Modelling, 28(7):677-695, 2004.

28. X. Litrico and V. Fromion. Simplified modeling of irrigation canals for controller design. Journal of Irrigation and Drainage Engineering, 130(5):373-383, 2004.

29. X. Litrico and D. Georges. Robust continuous-time and discrete-time flow control of a damriver system. (i) modelling. Applied Mathematical Modelling, 23(11):809-827, 1999.

30. N. C. van de Giesen M. Xu, P.-J. van Overloop. On the study of control effectiveness and computational efficiency of reduced Saint-Venant model in model predictive control of open channel flow. Advances in Water Resources, 2(34):282-290, 2010.

31. P.-O. Malaterre and J. P. Baume. SIC 3.0, a simulation model for canal automation design. In A. Mokhlisse, editor, International Workshop on Regulation of Irrigation Canals: State of art of research and applications, volume I, pages 68-75. L.A.A.A.-C.N.R.S., 19971997.

32. I. Mallidis, R. Dekker, and D. Vlachos. The impact of greening on supply chain design and cost: a case for a developing region. Journal of Transport Geography, 22(0):118 - 128, 2012.

33. MATLAB. version 7.10.0 (R2010a). The MathWorks Inc., Natick, Massachusetts, 2010.

34. S. Mihic, M. Golusin, and M. Mihajlovic. Policy and promotion of sustainable inland waterway transport in Europe - Danube River. Renewable and Sustainable Energy Reviews, 15(4):1801 - 1809, 2011.

35. F. Millerd. Global climate change and great lakes international shipping. Technical report, 2007.

36. S.J. Murray, P.N. Foster, and I.C. Prentice. Future global water resources with respect to climate change and water withdrawals as estimated by a dynamic global vegetation model. Journal of Hydrology, 448449(0): 14 - 29, 2012.

37. R. Negenborn, P.-J. van Overloop, T. Keviczky, and B. De Schutter. Distributed model predictive control of irrigation canals. Networks and heterogeneous media, 4(2):359-380, 2009.

38. C. Ocampo-Martinez. Model Predictive Control of Wastewater Systems. Advances in Industrial Control. Springer, 2010.

39. O. Le Pocher, E. Duviella, L. Bako, and K. Chuquet. Sensor fault detection of a real undershot/overshot gate based on physical and nonlinear black-box models. In SAFEPROCESS 8th IFAC International Symposium on Fault Detection, Supervision and Safety for Technical Purposes, Mexico City, Mexico, August 29-31. 2012.

40. O. Le Pocher, E. Duviella, and K. Chuquet. Sensor fault detection in a real hydraulic system using classification approach. In 11th International Conference on Informatics in Control, Automation and Robotics (ICINCO), Nordwijkerhout, The Netherlands, July 28-31. 2011.

41. V. Puig, J. Romera, J. Quevedo, C. M. Cardona, A. Salterain, E. Ayesa, I. Irizar, A. Castro, M. Lujan, P. Charbonnaud, P. Chiron, and J.-L. Trouvat. Optimal predictive control of water transport systems: Arrêt-Darré/Arros case study. Water science and technology, 60(8):21252133, 2009.

42. J. Schuurmans. Open-channel flow model approximation for controller design. Applied Mathematical Modelling, 19(9):525-530, 1995.

43. J. Schuurmans. Control of water levels in open channels. PhD thesis, Delft University of Technology, Delft, The Netherlands, 1997.

44. I.A.A. ten Broeke, C.P.M. Willems, and C.C. Glansdorp. River information services: a joint European effort to enhance safety and usability of the inland waterway. In Intelligent Transportation Systems, 2001. Proceedings. 2001 IEEE, pages 1108-1115, 2001. 
45. The Ministry of Ecology, Sustainable Development and Energy, France. Vigicrues : Information sur la vigilance "crues", 1999.

46. P.-J. van Overloop. Model predictive control on open water systems. PhD thesis, Delft University of Technology, Delft, The Netherlands, 2006.

47. P.-J. van Overloop. Real-time implementation of model predictive control on MaricopaStanfield irrigation and drainage district's WM canal. Journal of Irrigation and Drainage Engineering, 136(11):747-756, 2010.

48. P.-J. van Overloop and X. Bombois. Identification of properties of open water channels for controller design. In IFAC Symposium on System Identification, volume 16, pages 1019-1024, 2012.

49. P.-J. van Overloop, I. J. Miltenburg, X. Bombois, A. J. Clemmens, R. Strand, and N. van de Giesen. Identification of resonance waves in open water channels. Control Engineering Practice, 18(8):863-872, 2010.

50. P.-J. van Overloop, R.R. Negenborn, B. De Schutter, and N.C. van de Giesen. Predictive control for national water flow optimization in The Netherlands. In R.R. Negenborn, Z. Lukszo, and H. Hellendoorn, editors, Intelligent Infrastructures, volume 42 of Intelligent Systems, Control and Automation: Science and Engineering, chapter 17, pages 439-461. Springer, Dordrecht, The Netherlands, 2010.

51. P.-J. van Overloop, S. Weijs, and S. Dijkstra. Multiple model predictive control on a drainage canal system. Control Engineering Practice, 16(5):531-540, 2008.

52. S. Wang, S. Kang, L. Zhang, and F. Li. Modelling hydrological response to different landuse and climate change scenarios in the Zamu River basin of northwest China. Hydrological Processes, 22(14), 2008.

53. Stephen J Wright. Primal-dual interior-point methods, volume 54. Siam, 1997. 